\title{
ANTIMYCOBACTERIAL ACTIVITY OF A BREVIBACILLUS LATEROSPORUS STRAIN ISOLATED FROM A MOROCCAN SOIL
}

\author{
Mohammed Hassi ${ }^{1}$; Souraya El Guendouzi ${ }^{1}$; Abdelleatif Haggoud ${ }^{1}$; Susana David ${ }^{\text {2; }}$ Saad Ibnsouda ${ }^{\text {; }}$ Abdellah Houari ${ }^{1}$; \\ Mohammed Iraqui ${ }^{1^{*}}$
}

${ }^{1}$ Laboratoire de Biotechnologie Microbienne, Faculté des Sciences et Techniques de Fès, B.P: 2202, Fès, Maroc; ${ }^{2}$ Instituto Nacional de Saúde Dr. Ricardo Jorge (INSA,IP), 1649-016, Lisbon, Portugal.

Submitted: February 14, 2011; Approved: June 07, 2012.

\begin{abstract}
The treatment of tuberculosis has become more difficult with the worldwide spread of multidrug-resistant (MDR) and extensively drug-resistant (XDR) strains of Mycobacterium tuberculosis. Moreover, the prevalence of human disease caused by atypical mycobacteria has also increased in the past two decades and has further complicated the problem of the treatment of mycobacterial infections. It is therefore urgent to develop new highly active molecules against these bacteria. The present study reports the isolation from a Moroccan soil of a Bacillus strain that exhibits an important antimycobacterial activity. The strain was identified as Brevibacillus laterosporus using DNA sequencing of the 16S ribosomal RNA gene. The antimycobacterial activity was assigned to a substance with a protein nature. This nature was revealed using a liquid-liquid extraction with organic solvents, precipitation with ammonium sulfate and treatment with a protease. This study suggested the identification and the characterization of this active metabolite enabling therapeutic investigations further.
\end{abstract}

Key words: Mycobacteria; Antimycobacterial; Antibiotic; Brevibacillus.

\section{INTRODUCTION}

According to the latest report published by the World Health Organization (WHO) in 2009 (27), the incidence of tuberculosis (TB) worldwide is estimated at 9.27 million cases with a mortality of 1.7 million, including 0.2 million HIVpositive cases. Developing countries are the most affected, with approximately $95 \%$ of the cases and $99 \%$ of the deaths. Indeed, the estimated incidence is the highest in sub-Saharan Africa, followed by Southeastern Asia (18). In industrialized countries, tuberculosis has again become a major threat after the emergence of drug-resistant forms in the early 1990s. However, the incidence remains low and does not exceed an average of 17 cases per 100000 inhabitants (18).

The causes of failure in the control of this disease are multi-factorial and are primarily related to the advent of acquired immunodeficiency syndrome (AIDS), the relative effectiveness of the vaccine Bacille Calmette-Guérin (BCC) (2) and the expansion of multidrug-resistant and extensively drug-resistant strains of Mycobacterium tuberculosis (6). This

*Corresponding Author. Mailing address: Laboratoire de Biotechnologie Microbienne, Faculté des Sciences et Techniques de Fès, B.P: 2202, Fès.; Tel.: +212650775778 Fax:+212-535608214.; E-mail: mhiraqui@yahoo.fr 
resistance has been favored by the length of the currently available therapeutic schemes and by the inappropriate use of antibiotics.

A multidrug-resistant strain (MDR-TB) is defined as a strain resistant to at least the two major first-line TB drugs, isoniazid (INH) and rifampicin (RIF). If a MDR-TB strain is also resistant to at least one of the three second-line injectable TB drugs (capreomycin, kanamycin or amikacin) in addition to any one of the fluoroquinolones, the strain is considered to be extensively drug-resistant (XDR-TB) (16). It is urgent to develop new highly active molecules against $M$. tuberculosis, including MDR and XDR strains. These molecules must act rapidly, have a long half-life for intermittent administration and be capable of sterilizing the sites where the bacteria remain persistent (10).

Telluric microorganisms are the primary source of antibiotics (11). Bacillus is a bacterial genus that is abundant in soil and contains several species that produce a large number of antibiotics with different chemical structures (29). These antibiotics are mainly active against Gram-positive bacteria, but compounds such as polymyxin, colistin and circulin inhibit the growth of Gram-negative bacteria (3), while bacillomycin, mycobacillin and fungistatin are active against yeast and fungi (12). The antibiotics produced by Bacillus mainly have a peptidic nature, and the majority of them are produced by strains of Bacillus subtilis and Bacillus brevis (13).

The aim of this study was the isolation and identification of a strain of Brevibacillus laterosporus that exhibits an important antimycobacterial activity. Furthermore, This study aimed to determine the nature of the substance responsible for this activity. To our knowledge, this is the first report on a strain of Brevibacillus laterosporus showing an antimycobacterial activity.

\section{MATERIALS AND METHODS}

\section{Samples and microbial strains}

Soil samples were collected from ten Moroccan ecosystems. Using a large sterile spatula, the first five centimeters of the surface layer of the soil were removed. Then, with a small sterile spatula, 100 to $150 \mathrm{~g}$ of soil were taken from the subjacent layer at 5 to $15 \mathrm{~cm}$ of depth and deposited on a sterile aluminum sheet. The large debris, such as stones and roots, were eliminated, and approximately $50 \mathrm{~g}$ of the remaining material was placed in a sterile flask and transported as quickly as possible to the laboratory.

The microbial strains used in this study were:

- Mycobacterium aurum A+: a non-pathogenic Mybacterium species with a generation time of approximately $6 \mathrm{~h}$. This strain was used as a model to evaluate the effect of active substances on the growth of M. tuberculosis (4),

- Mycobacterium smegmatis mc(2)155: a non-pathogenic atypical mycobacterial strain with a generation time of approximately $3 \mathrm{~h}$,

- Mycobacterium kansasii ATCC 12478: an atypical mycobacterial strain causing opportunistic infections,

- Mycobacterium bovis BCG IP: the vaccine strain,

- Mycobacterium vaccae ATCC 1548314 and

- Escherichia coli DH5a.

The mycobacteria were cultivated at $37^{\circ} \mathrm{C}$ on Lowenstein Jensen medium or Sauton medium $(1,21)$.

The Escherichia coli strain was cultivated on Luria Bertani (LB) medium containing the following: peptone (Biokarps Diagnostics, Beauvais, France), $10 \mathrm{~g} / \mathrm{l}$; yeast extract (Biokarps Diagnostics, Beauvais, France), $5 \mathrm{~g} / \mathrm{l}$; and sodium chloride (Riedel- de Haën, Seelze, Germany), 10 g/l.

\section{Screening for bacterial strains with antimycobacterial activity}

To isolate bacterial strains with antimycobacterial activities, $4 \mathrm{~g}$ of each soil sample were dissolved in $36 \mathrm{ml}$ of sterile saline $(\mathrm{NaCl}, 9 \mathrm{~g} / \mathrm{l})$ and shaken for $2 \mathrm{~h}$ at ambient temperature. The supernatant was then recovered, and various dilutions were prepared in LB medium $\left(10^{-1}\right.$ to $\left.10^{-7}\right)$. A volume of $100 \mu \mathrm{l}$ of each dilution was plated onto LB agar previously seeded with approximately $10^{6} \mathrm{CFU} / \mathrm{ml}$ of $M$. aurum $\mathrm{A}+$ or $M$. 
smegmatis cultures. After incubation at $37^{\circ} \mathrm{C}$ for $48 \mathrm{~h}$, the bacterial clones surrounded by inhibition zones were recovered. One of these clones showed strong activity and was maintained for this work.

\section{Antimycobacterial activity assay}

The isolated clone was cultivated under agitation on LB medium at $37^{\circ} \mathrm{C}$ for $24 \mathrm{~h}$. A volume of $10 \mathrm{ml}$ of the bacterial culture was centrifuged for $10 \mathrm{~min}$ at $6000 \mathrm{~g}$. The supernatant was then recovered and sterilized by filtration. The antimycobacterial activity was evaluated using an agar well diffusion assay on plates pre-seeded with the indicator strains, M. aurum A+ or M. smegmatis (23).

The agar wells were filled with $100 \mu \mathrm{l}$ of the prepared filtrates (20). The zones of inhibition were analyzed after $72 \mathrm{~h}$ of incubation at $37^{\circ} \mathrm{C}$. Each test was repeated 3 times. For the negative control, an E. coli culture filtrate was used.

The antimycobacterial activity was also studied after a liquid-liquid extraction using ethyl acetate and ether solvents. The isolated clones were cultivated under agitation on LB medium at $37^{\circ} \mathrm{C}$ for $48 \mathrm{~h}$. A volume of $100 \mathrm{ml}$ of the bacterial culture was centrifuged for $10 \mathrm{~min}$ at $6000 \mathrm{~g}$. Then, the supernatant was recovered, sterilized by filtration and added to $100 \mathrm{ml}$ of organic solvent, either ethyl acetate or ether. After agitation for one hour at room temperature, the organic extract obtained was evaporated under vacuum at $37^{\circ} \mathrm{C}$. The dry residue was taken up in $1 \mathrm{ml}$ of sterile distilled water and filtered. The antimycobacterial activity was measured using the agar well diffusion assay on plates pre-seeded with the indicator strains, M. aurum $\mathrm{A}+$ and M. smegmatis, as described above. For the negative control, an E. coli culture filtrate was used.

\section{Kinetics of the active substance production}

The bacterial growth was assessed by monitoring the optical density at $595 \mathrm{~nm}\left(\mathrm{O}_{595} \mathrm{~nm}\right)$. To determine the kinetics of the production of the active substance, a colony of the tested bacterial strain was inoculated in a volume of $100 \mathrm{ml}$ of LB medium and incubated at $37^{\circ} \mathrm{C}$ for $12 \mathrm{~h}$. This culture was diluted $10^{4}$ fold in a volume of 21 of fresh LB medium and incubated at $37^{\circ} \mathrm{C}$ under moderate agitation. At regular time intervals, $100 \mathrm{ml}$ of this culture was recovered and a liquidliquid extraction using ether was performed as previously described. A volume of $100 \mu \mathrm{l}$ of the organic extract was then deposited in wells on Sauton agar medium already pre-seeded with $M$. aurum A+ $\left(\mathrm{O}_{595 \mathrm{~nm}}\right.$ : 0.2). The diameters of inhibition were measured after $72 \mathrm{~h}$ of incubation at $37^{\circ} \mathrm{C}$.

\section{Identification of the antimycobacterial-producing strain}

To identify the antimycobacterial-producing strain, amplification and sequencing of the $16 \mathrm{~S}$ rRNA gene was performed. The use of $16 \mathrm{~S}$ rRNA is a powerful tool that has been used to identify bacteria from various sources, such as environmental or clinical specimens, and to establish phylogenetic relationships between bacteria $(5,19,25,28)$. The DNA extraction from bacteria was carried out according to a standard method (17). For the PCR amplification, the universal primers fD1 (5' - AGAGTTTGATCCTGGCTCAG-3') and rP2 (5'-TACGGCTACCTTGTTACGACTT- 3') were used to amplify a $1.5-\mathrm{kb}$ fragment of the $16 \mathrm{~S}$ rDNA $(9,26)$. The PCR was performed under the following conditions: $94^{\circ} \mathrm{C}$ for $5 \mathrm{~min}$, 35 cycles of $94^{\circ} \mathrm{C}$ for $45 \mathrm{~s}, 55^{\circ} \mathrm{C}$ for $1 \mathrm{~min}$ and $72^{\circ} \mathrm{C}$ for $2 \mathrm{~min}$ and finally $72^{\circ} \mathrm{C}$ for $10 \mathrm{~min}$.

For sequencing, the PCR products were purified using a PCR product purification kit according to the manufacturer (JETquick, Genomed). The sequencing reaction mixture contained $2.0 \mu \mathrm{L}$ of BigDye $\mathrm{V} 1.1,2.7 \mu \mathrm{L}$ of the PCR product and $0.5 \mu \mathrm{M}$ of the primer, either $\mathrm{fD} 1$ or $\mathrm{rP} 2$. A final reaction volume of $10 \mu \mathrm{L}$ was used. The amplification conditions included an initial denaturation at $96^{\circ} \mathrm{C}(3 \mathrm{~min})$ followed by 35 cycles of denaturation at $96^{\circ} \mathrm{C}(20 \mathrm{~s})$, annealing at $50^{\circ} \mathrm{C}(5 \mathrm{~s})$ and extension at $60^{\circ} \mathrm{C}(4 \mathrm{~min})$. The sequencing of the PCR products was performed on an ABI PRISM sequencing apparatus (ABI Prism 310 Genetic Analyzer, Applied Biosystems), and the data analysis was completed using sequencing analysis software. 
Characterization of the protein nature of the antimycobacterial metabolite

The bacterial strain was grown in $100 \mathrm{ml}$ of LB medium at $37^{\circ} \mathrm{C}$ until the early stationary phase. The cells were removed by centrifugation for $10 \mathrm{~min}$ at $6000 \mathrm{~g}$ and $4^{\circ} \mathrm{C}$, and the supernatant was recovered and filtered using a $0.22-\mu \mathrm{m}$ filter (Millipore, Molsheim, France).

A precipitation with $80 \%$ saturated ammonium sulfate was carried out overnight at $4^{\circ} \mathrm{C}$ under agitation (29). The resulting precipitate was harvested by centrifugation at $10000 \mathrm{~g}$ for $20 \mathrm{~min}$ at $4^{\circ} \mathrm{C}$, resuspended in $1 \mathrm{ml}$ of potassium phosphate buffer (50 mM; $\mathrm{pH} 6)$ and dialyzed against the same buffer at $4^{\circ} \mathrm{C}$ for $24 \mathrm{~h}$. The buffer was renewed several times to facilitate a better dialysis. The antimycobacterial activity of the resulting precipitate was measured using the agar well diffusion assay on plates pre-seeded with the indicator strain $M$. aurum $\mathrm{A}+$ (O.D $595 \mathrm{~nm}: 0.2)$.

The diameters of inhibition were determined after $72 \mathrm{~h}$ of incubation at $37^{\circ} \mathrm{C}$. This experiment was repeated twice. The control that was used corresponded to a dialyzed product obtained from an E. coli culture prepared in the same conditions as the test strain. The proteins in the resulting precipitate were quantified using the Lowry method (15) and analyzed using sodium dodecyl sulfate polyacrylamide gel electrophoresis (SDS-PAGE).

To establish the protein nature of the antimycobacterial metabolite, the metabolite was also tested for its sensitivity to proteinase K (29). Two controls were used: (1) the ammonium sulfate extract untreated by proteinase $\mathrm{K}$ and (2) proteinase $\mathrm{K}$ without the extract. The samples were incubated in the presence of proteinase $\mathrm{K}(1 \mathrm{mg} / \mathrm{ml})$ at $37^{\circ} \mathrm{C}$ for $3 \mathrm{~h}$. The antimycobacterial effect of these preparations was examined using the agar well diffusion assay against $M$. aurum $\mathrm{A}+$ as previously described.

\section{RESULTS AND DISCUSSION}

\section{Isolation of a bacterial strain with antimycobacterial activity}

Telluric microorganisms were the principal source of antibiotics discovered in the second half of the 20th century (13). In this work, we chose particular biotopes to isolate bacteria that express antimycobacterial activity. A clone surrounded by an inhibition zone was obtained on LB-agar medium pre-seeded with $M$. smegmatis. Furthermore, the filtrate prepared from the isolated clone was able to inhibit the growth of $M$. smegmatis and $M$. aurum A+ (Table 1), indicating that the active substance was secreted by the clone. The filtrate was also active against $M$. vaccae, $M$. bovis BCG and $M$. kansasii (data not shown). In addition, the ethyl acetate and ether extracts showed a more accentuated antimycobacterial activity than that of the filtrate (Table 1), indicating that the solvents were capable of extracting and concentrating the active substance responsible for the observed biological activity.

The production kinetics of the active substance were also studied (Fig. 1). The antimycobacterial activity was detected after six hours and increased progressively during the exponential phase of growth. The maximum activity was reached after $24 \mathrm{~h}$ of growth and then decreased rapidly. These results (Table 1, Fig. 1) indicate that the active substance, responsible for the observed antimycobacterial effect, is synthesized during the exponential phase and early stationary phase.

Table 1. Antimycobacterial activity of the bacterial isolate (measured in $\mathrm{mm}$ ).

\begin{tabular}{cccc}
\hline Microorganism & Filtrate & Ethyl acetate extract & Ether extract \\
\hline M. smegmatis & $10 \pm 0.5$ & $32 \pm 0.0$ & $33 \pm 1.5$ \\
M. aurum A+ & $11.5 \pm 0.7$ & $34.5 \pm 2.12$ & $35 \pm 0.7$ \\
\hline The data are average values of triplicates \pm one standard deviation & &
\end{tabular}

The data are average values of triplicates \pm one standard deviation. 


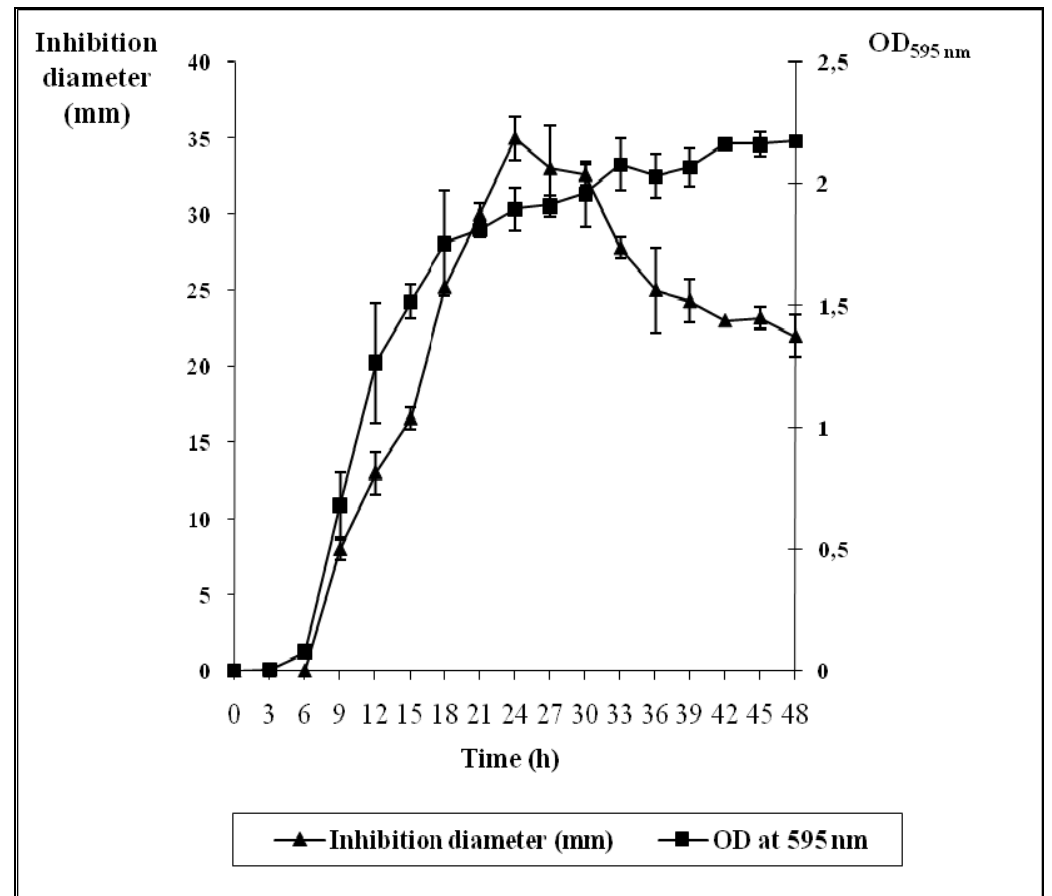

Figure 1. Time course of the antimycobacterial metabolite production by the bacterial isolate.

Molecular identification of the antimycobacterial-producing isolate

The lengths of the 16S rDNA sequences analyzed were 713 $\mathrm{bp}$ and $648 \mathrm{bp}$ for the primers fD1 and rP2, respectively. Their analysis in comparison with the sequences available in Gen Bank, EMBL, DDJB and PDB databases showed that the antimycobacterial-producing strain was closely related to Brevibacillus laterosporus species with $100 \%$ similarity (accession number: DQ371289.2).

Characterization of the protein nature of the antimycobacterial metabolite

The protein extract of the Brevibacillus laterosporus strain was prepared and shown to be capable of inhibiting $M$. aurum $\mathrm{A}+$ growth (Table 2). Moreover, this activity was totally lost in the presence of proteinase $\mathrm{K}$ (Table 2). The same result was also obtained after treatment of the organic extracts, obtained with ethyl acetate and ether, with proteinase $\mathrm{K}$ (Table 2). This result indicates that the bioactive metabolite secreted by the Brevibacillus strain is of a protein nature.

The concentration of the protein extract was determined to be $0.0104 \mathrm{mg} / \mathrm{ml}$. An analysis of the extract using polyacrylamide gel electrophoresis revealed the presence of nine bands (Fig. 2) with molecular weights comprised between 40 and $240 \mathrm{kDa}$. These bands were absent in the control, an E. coli protein extract. These results (Table 2, Fig. 2) indicate that the antimycobacterial activity of the bacterial isolate could be due to one protein or the synergistic action between two or more of these proteins.

Table 2. Characterization of the protein nature of the antimycobacterial metabolite.

\begin{tabular}{ccccccc}
\hline & \multicolumn{5}{c}{ Inhibition diameters against M. aurum A+ (mm) } \\
\cline { 2 - 6 } & $\begin{array}{c}\text { Without treatment } \\
\text { with proteinase K }\end{array}$ & $\begin{array}{c}\text { After treatment } \\
\text { with proteinase K }\end{array}$ & T1 & Controls & T2 & T3 \\
\hline ASP & $33 \pm 0.7$ & 0 & 0 & 0 & 0 \\
EAE & $34.5 \pm 1.5$ & 0 & 0 & 0 & 0 \\
EE & $24.5 \pm 0.0$ & 0 & 0 & 0 & 0 \\
\hline
\end{tabular}

ASP: ammonium sulfate precipitate; EAE: ethyl acetate extract; EE: ether extract; T1: ammonium sulfate precipitate of sterile LB medium; T2: ammonium sulfate precipitate of LB medium inoculated with E. coli; T3: proteinase K solution. The data are average values of duplicates \pm one standard deviation. 
Bacillus species produce approximately 167 biological compounds (12). Brevibacillus laterosporus comb. nov. (24), previously classified as Bacillus laterosporus (Laubach 1916), has demonstrated a very wide spectrum of biological activity (7). Several antibiotics produced by Brevibacillus laterosporus have been described, such as laterosporamine, laterosporin (12), tauramamide and loloatin A.

Tauramamide is a lipopeptide antibiotic active against pathogenic Enterococcus sp (8), while loloatin A was identified as a cyclic decapeptide with cyanolytic activity (14). Moreover, an antimicrobial substance produced by a Brevibacillus laterosporus strain isolated from a marine habitat was recently purified and characterized. The antimicrobial substance had high activities against Gram-positive bacteria, such as Streptococcus, Staphylococcus aureus and Clostridium; Gram-negative bacteria, such as Escherichia coli and Pseudomonas putrefaciens; and against Candida albicans (22).

As previously described, the Brevibacillus laterosporus strain isolated in this work is able to secrete an active substance of a protein nature that inhibits the growth of various mycobacteria. To our knowledge, this study is the first report describing such a substance produced by a strain of $B$. laterosporus. Based on this study, our goal is to test the antimycobacterial metabolite on $M$. tuberculosis and on mycobacteria hosted by macrophages. Moreover, the identification and the characterization of this compound would facilitate further therapeutic investigations.

\section{REFERENCES}

1. Allen, B.W. (1998). Mycobacteria: general culture methodology and safety considerations. Methods Mol. Biol. 101, 15-30.

2. Billy, C.; Lévy-Bruhl, D. (2007). Vaccin BCG et place de 1'intradermoréaction en 2006. La Revue de médecine interne. 28 (3), 151-160

3. Bottone, E.J.; Peluso, R.W. (2003). Production by Bacillus pumilus (MSH) of an antifungal compound that is active against Mucoraceae and Aspergillus species: preliminary report. J. Med. Microbiol. 52 (Pt 1), 6974.
4. Chung, G.A.; Aktar, Z.; Jackson, S.; Duncan, K. (1995). High throughput screen for detecting antimycobacterial agents. Antimicrob. Agents. Chemother. 39 (10), 2235-2238.

5. Clarridge, J.E. (2004). Impact of 16S rRNA gene sequence analysis for identification of bacteria on clinical microbiology and infectious diseases. Clin. Microbiol. Rev. 17(4), 840-862.

6. Danilchanka, O.; Mailaender, C.; Niederweis, M. (2008). Identification of a novel multidrug efflux pump of Mycobacterium tuberculosis. Antimicrob. Agents. Chemother. 52(7), 2503-2511.

7. de Oliveira, E.J.; Rabinovitch, L; Monnerat, R.G.; Passos, L.K.J.; Zahner, V. (2004). Molecular characterization of Brevibacillus laterosporus and its potential use in biological control. Appl. Environ. Microbiol. 70 (11), 6657-6664.

8. Desjardine, K.; Pereira, A.; Wright, H.; Matainaho, T.; Kelly, M.; Andersen, R.J. (2007). Tauramamide, a lipopeptide antibiotic produced in culture by Brevibacillus laterosporus isolated from a marine habitat: structure elucidation and synthesis. J. Nat. Prod. 70 (12), 1850-1853.

9. Drancourt, M.; Bollet, C.; Carlioz, A.; Martelin, R.; Gayral, J.P.; Raoult, D. (2000). 16S ribosomal DNA sequence analysis of a large collection of environmental and clinical unidentifiable bacterial isolates. J. Clin. Microbiol. 38 (10), 3623-3630.

10. Dutta, N.K.; Dastidar, S.G.; Kumar, A.; Mazumdar, K.; Ray, R.; Chakrabarty, A.N. (2004): Antimycobacterial activity of the antiinflammatory agent diclofenac sodium, and its synergism with streptomycin. Braz. J. Microbiol. 35, 316-323.

11. Gillespie, D.E.; Brady, S.F.; Bettermann, A.D.; Cianciotto, N.P.; Liles, M.R.; Rondon, M.R.; Clardy, J.; Goodman, R.M.; Handelsman, J. (2002). Isolation of antibiotics turbomycin A and B from a metagenomic library of soil microbial DNA. App. Environ. Microbiol. 68 (9), 43014306.

12. Katz, E.; Demain, A.L. (1977). The peptide antibiotics of Bacillus: chemistry, biogenesis and possible functions. Bacteriol. Rev. 41 (2), 449474.

13. Kleinkauf, H.; von Döhren, H. (1990). Nonribosomal biosynthesis of peptide antibiotics. Euro. J. Biochem. 192 (1), 1-15.

14. Krachkovskiı̌, S.A.; Sobol', A.G.; Ovchinnikova, T.V.; Tagaev, A.A.; Iakimenko, Z.A.; Azizbekian, R.R.; Kuznetsova, N.I.; Shamshina, T.N.; Arsen'ev, A.S. (2002). Isolation, biological properties, and spatial structure of an antibiotic loloatin A. Bioorg. Khim. 28 (4), 298-302.

15. Lowry, O.H.; Rosebrough, N.J; Farr A. L.; Randall, R.J. (1951). Protein measurement with the Folin phenol reagent. J. Biol. Chem. 193 (1), 265275.

16. Marigot-Outtandy, D.; Perronne, C. (2009). Les nouveaux antituberculeux. Réanimation. 18 (4), 334-342.

17. Marmur, J. (1961). A procedure for the isolation of deoxyribonucleic acid from microorganisms. J. Mol. Biol. 3 (2), 208-218.

18. Martinez, V.; Gicquel, B. (2005). Techniques diagnostiques de la 
tuberculose et des autres mycobactérioses. Arch. Pediatr. 12, 96-101.

19. Mignard, S.; Flandrois. J.P. (2006). 16S rRNA sequencing in routine bacterial identification: a 30-month experiment. J. Microbiol. Methods. 67 (3), 574-581.

20. Motta, A.S.; Cladera-Olivera, F.; Brandelli, A. (2004): Screening for antimicrobial activity among bacteria isolated from the Amazon Basin. Braz. J. Microbiol. 35, 307-310.

21. Papa, F.; Rivière, M.; Fournié, J.J.; Puzo, G.; David, H. (1987). Specificity of a Mycobacterium kansasii phenolic glycolipid (mycoside A) immunoserum. J. Clin. Microbiol. 25 (12), 2270-2273.

22. Ren, Z.Z.; Zheng, Y.; Sun, M.; Liu, J.Z.; Wang, Y.J. (2007). Purification and properties of an antimicrobial substance from marine Brevibacillus laterosporus Lh-1. Wei. Sheng. Wu. Хue. Bao. 47 (6), 9971001.

23. Sánchez, J. G. B.; Kouznetsov, V. V. (2010): Antimycobacterial susceptibility testing methods for natural products research. Braz. J. Microbiol. 41 (2), 270-277.

24. Shida, O.; Takagi, H.; Kadowaki, K.; Komagata, K. (1996). Proposal for two new genera, Brevibacillus gen. nov. and Aneurinibacillus gen. nov.
Int. J. Syst. Bacteriol. 46, (4), 939-946.

25. Wang, W.; Sun, M. (2009). Phylogenetic relationships between Bacillus species and related genera inferred from 16s rDNA sequences. Braz. J. Microbiol. 40, 505-521.

26. Weisberg, W.G.; Barns, S.M.; Pelletier, D.A.; Lane, D.J. (1991). 16S ribosomal DNA amplification for phylogenetic study. J. Bacteriol. 173 (2), 679-703.

27. WHO Report. (2009). Global tuberculosis control - epidemiology, strategy, financing. WHO/HTM/TB/2009.411. Available at: http://www.who.int/tb/publications/global_report/2009/en/. Accessed August 21, 2010.

28. Woo, P.C. ; Lau, S.K.; Teng, J.L.; Tse, H.; Yuen, K.Y. (2008). Then and now: use of $16 \mathrm{~S}$ rDNA gene sequencing for bacterial identification and discovery of novel bacteria in clinical microbiology laboratories. Clin. Microbiol. Infect. 14 (10), 908-934.

29. Wu, S.; Jia, S.; Sun, D.; Chen, M.; Chen, X.; Zhong, J.; Huan, L. (2005). Purification and characterization of tow novel antimicrobial peptides Subpeptin $\mathrm{JM}_{4}-\mathrm{A}$ and Subpeptin $\mathrm{JM}_{4}-\mathrm{B}$ produced by Bacillus subtilus $\mathrm{JM}_{4}$, Curr. Microbiol. 51 (5), 292- 296. 